\title{
Familles lyonnaise victimes du siège de Lyon en
}

\section{3}

\section{Michel Biard}

\section{Q OpenEdition \\ 1 Journals}

\section{Édition électronique}

URL : https://journals.openedition.org/ahrf/2161

DOI : 10.4000/ahrf.2161

ISSN : 1952-403X

Éditeur :

Armand Colin, Société des études robespierristes

\section{Édition imprimée}

Date de publication : 1 mars 2005

Pagination : 170-172

ISSN : 0003-4436

\section{Référence électronique}

Michel Biard, «Familles lyonnaise victimes du siège de Lyon en 1793 », Annales historiques de la

Révolution française [En ligne], 339 | janvier-mars 2005, mis en ligne le 24 avril 2006, consulté le 24 avril 2022. URL : http://journals.openedition.org/ahrf/2161 ; DOI : https://doi.org/10.4000/ahrf.2161

Ce document a été généré automatiquement le 24 avril 2022.

Tous droits réservés 


\title{
Familles lyonnaise victimes du siège de Lyon en 1793
}

\author{
Michel Biard
}

\section{RÉFÉRENCE}

Hervé De Christen, Familles lyonnaise victimes du siège de Lyon en 1793, Paris, Éd. Christian, 2004, 298 p., 29 e.

Dans la lignée des recherches entreprises par l'association « Lyon 93 » sur les victimes du siège de Lyon entre août et octobre 1793, divers généalogistes ont multiplié les travaux sur les familles touchées par les affrontements militaires ou/et par la répression qui a suivi la reprise de la ville. Les écrits issus de ces recherches ont très souvent le défaut d'être entachés d'une vision qui persiste deux siècles après dans une hostilité sans nuance à la Révolution française, mais ils n'en apportent pas moins des connaissances souvent fort utiles. On aimerait simplement davantage d'objectivité et de rigueur historique, comme en avaient par exemple fait preuve en 1993 les auteurs du catalogue d'exposition 1793 : l'année terrible à Lyon (exposition du Musée de l'imprimerie et de la banque). C'est toutefois dans ce courant de recherches hostile à la Révolution française que doit être inscrit le livre d'Hervé de Christen, qui évoque quatre familles lyonnaises : les Pessonneaux, les Dujast, les Chaney et les Janmot. Aussi, pour pouvoir tirer tout l'intérêt - bien réel - de ce livre, convient-il çà et là de faire abstraction de quelques appréciations à l'emporte-pièce (pour oser ici le mot), comme à la page 11 où une batterie des troupes assiégeantes est qualifiée de "batterie ennemie » en vertu d'un langage qui semble vouloir faire décidément durer les haines, ou encore lorsque l'auteur évoque avec lyrisme les « profondeurs de l'âme lyonnaise » (qu'est-ce?).

Les quatre cinquièmes de l'ouvrage sont strictement consacrés à l'étude généalogique, très poussée, fruit de longues et remarquables recherches, qui court du xvII siècle à nos jours. Si les destinées de ces familles au $\mathrm{xx}^{\mathrm{e}}$ siècle ne retiendront guère l'attention des lecteurs des A.H.R.F., en revanche les quelque soixante pages de l'introduction sont 
intéressantes dans la mesure où elles permettent de découvrir tout un réseau familial et social patiemment tissé entre Saône et Rhône, mais aussi bien sûr plusieurs destins individuels face à la tourmente de l'été et de l'automne 1793. Pour Claude-Marie Chaney, le destin met surtout en lumière la crise de la fabrique lyonnaise à la veille de la Révolution. Marchand fabricant en étoffes de soie lors de son mariage en 1774, l'homme est donné comme simple commis en 1791, puis ouvrier en soie en 1794. Dans l'absolu, on pourrait penser à quelque dissimulation en un moment, 1793-1794, où être « riche » à Lyon n'est pas forcément une situation idéale, toutefois l'acte d'accusation dressé contre lui après le siège le décrit comme un «très pauvre père de trois enfants, esprit faible et fanatique ». Cette fidélité à l'Église, en un temps où les réfractaires bénissaient les résistances à la Révolution, aurait pu lui valoir de bien pires ennuis que les deux mois et demi d'emprisonnement qu'il subit entre brumaire et pluviôse, avant que le comité de surveillance de sa section ne propose son élargissement, "attendu [qu'il n'a] aucune intention de nuire au bien général ». Interné en même temps que lui, Antoine Pessonneaux ne bénéficie pas de la même mansuétude, mais encore faut-il constater que les catégories sociales ne sont pas identiques! Négociant, par ailleurs propriétaire de forges en Saône-et-Loire et en Isère, l'homme dispose à la veille de la Révolution d'une fortune estimée par l'auteur à 100000 livres, loin, très loin, des moyens restés à Chaney à ce moment. Antoine Pessonneaux, à en croire ses descendants, aurait été arrêté à la mi-novembre 1793, donc un bon mois après la prise de la ville, dissimulé dans une barrique chargée sur un bateau à quai. Aussi, non content d'avoir à assumer son statut de "riche ", il fait partie de ceux qui ont cherché à fuir. De quoi l'envoyer à la mort? Apparemment non, si l'on en croit le premier rapport fait sur son cas: «Pessonneaux, maître de forges quai de Saône $n^{\circ} 46$. Disons qu'il est un peu dévot, mais d'une conscience pure. A été dans le principe trésorié pour les pauvres dans sa section et aurait continué à l'être pendant le siège. Peut éclairé sur la Révolution. A pu assez facilement tombé dans le piège des contre-révolutionnaires. Comme il n'est point égoïste il fera sans peine et par caractère le sacrifice que la nation exigera de lui ». Une proposition de libérer ce "philanthrope" à reconvertir ainsi en "philanthrope républicain et régénéré" est faite le 4 nivôse an II (24 décembre 1793), puisque son nom est inscrit sur une liste de captifs à élargir qui comporte aussi celui de son co-détenu Chaney. Hélas pour lui, son patronyme est biffé d'un coup de plume et il présente sa tête au « rasoir national » trois semaines plus tard, le 27 nivôse (16 janvier 1794), deux semaines avant que Chaney soit libéré. De toute évidence, il y a bien là deux cas d'individus somme toute peu compromis dans le soulèvement lyonnais, mais dont la position sociale entraîne un sort opposé dans cette cité devenue Ville-Affranchie où la Commission temporaire de surveillance républicaine, dans sa célèbre Instruction, proclame: "Il est bien aisé de comprendre que par le peuple, on n'entend pas cette classe privilégiée par ses richesses, qui avait usurpé toutes les jouissances de la vie et tous les biens de la société. Le peuple est l'universalité des citoyens français ; le peuple, c'est surtout la classe immense du pauvre [...] ». Le 28 nivôse, Achard, révolutionnaire lyonnais, écrit à propos de l'exécution de la veille: "Le tribunal poursuit avantageusement sa carrière [...] hier dix-sept ont mis la tête à la chatière; et, aujourd'hui, huit y passent et vingt et un reçoivent le feu de la foudre ». Parmi les dixsept, outre Pessonneaux, se trouvaient Pierre Chamon, « homme de peine » simplement surpris avec un faux passeport, et Cochet, épicier, qui avait participé aux combats... on le voit, ce sont là dix-sept têtes qui tombent, mais combien de cas différents, victimes d'une lutte devenue inexpiable depuis le printemps et l'été $1793 . .$. 
3 Parmi ces familles « victimes du siège de Lyon » étudiées par l'auteur, citons enfin un " jeune héros du siège de Lyon », Barthélemy Dujast. Le jeune homme (né en 1775), issu d'une famille de fabricants de draps de soie, s'illustre en effet par un coup de main audacieux contre les troupes assiégeantes, dans la nuit du 1er au 2 septembre. Avec un compagnon, la tête entourée de fusées incendiaires enveloppées d'une toile enduite de goudron, il parvient à traverser le Rhône à la nage, à détruire par le feu « cinq ou six chantiers " qui abritaient une batterie des forces républicaines, puis à regagner la presqu'île à la nage en dépit d'une jambe brûlée. Si l'on ajoute que le lendemain les deux hommes refusent la récompense de 20000 livres que leur offrent Précy et son état-major, et proclament qu'ils n'accepteront que des armes pour continuer la lutte... on est là, indubitablement, face à ce type de faits d'armes qu'affectionnent les épopées guerrières, qu'elles soient blanches ou bleues. Mort en 1861, Barthélemy Dujast avait été portraituré en 1851 par son neveu, le peintre lyonnais Louis Janmot, qui souhaitait permettre " aux Lyonnais de se rappeler avec reconnaissance le nom et les traits de leurs héroïques ancêtres, défenseurs de leur ville contre l'invasion des barbares et des bourreaux de 1793 ». Lorsque l'on sait que cette phrase est extraite du testament du peintre rédigé dans les années 1880, au temps de la République retrouvée, on comprend aisément à quel point les jeux de la mémoire (une mémoire pour le moins étroitement partisane) étaient à l'œuvre, de ces jeux qui n'ont pas transformé Lyon en "régionmémoire » comme la "Vendée ", mais qui expliquent sans aucun doute la difficulté d'écrire sereinement aujourd'hui encore sur l'histoire de cette ville en 1793-1794 ! 